\title{
Analysis on Influencing Factors of Campus Recruitment Effectiveness
}

\author{
Guo Zhiqin ${ }^{1, *}$, Zhang Xue ${ }^{1}$ \\ 1.School of Business Administration, Hohai University, Changzhou Jiangsu, China \\ *email: 20111843@hhu.edu.cn
}

\begin{abstract}
To improve effectiveness of campus recruitment is essential for graduating students, but campus recruitment results of many companies are unsatisfactory. Meanwhile, graduating students have low signing rate in campus recruitment. This paper explores the multiple factors that affect effectiveness of campus recruitment from the perspective of graduating students, collects data through questionnaire and conducts empirical research, finally determines the factors that affect effectiveness of campus recruitment at the graduating student level, and puts forward recommendations for improving effectiveness of campus recruitment of graduating students.
\end{abstract}

Key words: graduating students; campus recruitment; effectiveness

\section{Introduction}

Graduating students constitute talents that cannot be ignored in this emerging age, but in many campus recruitments, signing rate and quality are not high because graduating students have imperfect campus recruitment preparation and follow-up work, etc. which makes implementation effect of campus recruitment undesirable. Ultimately, not only graduating students have long and difficult job-hunting, but also campus recruitment cost is increased for enterprises, which is not conducive to sustainable development of enterprises. Therefore, the study on effectiveness of campus recruitment has become a common concern of all sectors of society. On the one hand, it helps graduating students start from campus recruitment efficiency, make reverse thinking from their own, find the root causes of failure, deepen understanding towards campus recruitment and their own, and strive to efficiently find desirable employment, improve signing rate and reduce turnover rate after the entry; on the other hand, investigation from the perspective of graduating students can help enterprises have a clear understanding of needs of graduating students, purposefully adjust the details of the recruitment process, reduce the risk of personnel recruitment and select the right people.

\section{Questionnaire design}

Whether campus recruitment is effective is mainly affected by the following factors.

\subsection{Job-hunting skills}

This skill mainly includes resume crafting skills, interview skills. Some graduating students imitate resume templates on the network when crafting resume, but many words are empty useless cliches. In the interview process, some job seekers are too nervous due to inadequate preparation, fail to display their own advantages and are eliminated, but there are job seekers hired due to good expression, outstanding on-the-spot performance.

\subsection{Job expectations}

Many candidates are more focused on positions with higher wages and larger development space in job hunting. In addition, candidates' expectations towards salary and benefits of the position will also affect effectiveness of campus recruitment.

\subsection{Adaptability}

As the market environment is changing at all times, companies have higher requirements for self-adjustment ability of candidates. Whether one has this ability is also one indicator for employer to assess whether the candidate is competent for the job. 


\subsection{Work ability}

In the current campus recruitment, more and more employers pay more attention to candidates' work ability, rather than simply look at their academic level, or just determine their ability from the interview process.

Therefore, in the questionnaire design, a total of 11 questions related to the above four factors are refined.

Table 1 Questionnaire subject design

\begin{tabular}{|c|c|c|}
\hline Influencing factors & Sub-factors & Corresponding title number \\
\hline \multirow{6}{*}{ Expectations towards the job } & Resume-crafting skills & 1 \\
\hline & Interview Skills & $2 、 3$ \\
\hline & $\begin{array}{l}\text { Overall development } \\
\text { prospects of the enterprise }\end{array}$ & 4 \\
\hline & $\begin{array}{c}\text { Corporate brand image and } \\
\text { prestige }\end{array}$ & 5 \\
\hline & $\begin{array}{l}\text { Position development, } \\
\text { promotion space }\end{array}$ & 6 \\
\hline & Salary level of position & 7 \\
\hline Adaptability & Environmental Adaptability & $8 、 9$ \\
\hline Work ability & Practical work ability & 10、 11 \\
\hline
\end{tabular}

\section{Empirical research}

In this paper, the survey was conducted among graduating students who find employment through campus recruitment and work for more than a month after signing the contract. A total of 136 questionnaires were issued, 121questionnaires were recovered, effective questionnaires numbered 109, and the effective recovery rate was $80.15 \%$.

Bartlett and KMO tests were conducted on the questionnaires of influencing factors in campus recruitment of graduating students. KMO value of the questionnaire is 0.795 , that is, correlation between the variables is strong. Bartlett spherical test value of the questionnaire is $1.323 \mathrm{E} 3$, that is, correlation coefficient is significant. The degree of freedom is $55, \mathrm{P}=0.000$ which is significant, so the scale is suitable for factor analysis.

The principal factor analysis method was used to extract the common factor. Table 1 is the eigenvalue and variance contribution table, in which eigenvalues of the four factors are greater than 1 , and the four common factors can explain $89.835 \%$ of total variance, so the first four common factors are chosen for analysis.

Table 2:Total Variance Explained

\begin{tabular}{|l|r|r|r|r|r|r|}
\hline \multirow{2}{*}{$\begin{array}{l}\text { Compo } \\
\text { nent }\end{array}$} & \multicolumn{2}{|c|}{ Extraction Sums of Squared Loadings } & \multicolumn{3}{|c|}{ Rotation Sums of Squared Loadings } \\
\cline { 2 - 7 } & Total & \% of Variance & Cumulative \% & Total & \% of Variance & Cumulative \% \\
\hline 1 & 5.490 & 49.910 & 49.910 & 3.504 & 31.859 & 31.859 \\
2 & 2.016 & 18.326 & 68.236 & 2.832 & 25.747 & 57.606 \\
3 & 1.317 & 11.976 & 80.212 & 1.990 & 18.092 & 75.698 \\
4 & 1.059 & 9.624 & 89.835 & 1.555 & 14.138 & 89.835 \\
\hline
\end{tabular}

Extraction Method: Principal Component Analysis.

Through the factor load matrix, it is found that the factor variables have higher load on most variables, and the four principal components are extracted.

After the factor load matrix is rotated according to the variance maximum method, it can be seen that factor 1 has a large load on questions 5, 6 and 7, all of which reflect the attitude towards the candidate unit and can be 
named as "expectation towards the position". Factor 2 has a large load on questions 1 and 2, all of which reflect the factors in the job-hunting process and can be named as "job-hunting skills". Factor 3 has a large load on questions 8 , 9, all of which reflect adaptability factors after entry and can be named as "adaptability". Factor 4 has a large load on questions 10, 11, all of which reflect factors of work ability after entry and can be named as "work ability".

Table 3:Rotated Component Matrix ${ }^{\mathbf{a}}$

\begin{tabular}{|l|r|r|r|r|}
\hline & \multicolumn{4}{|c|}{ Component } \\
\cline { 2 - 5 } & 1 & 2 & 3 & \multicolumn{1}{c|}{4} \\
\hline Question1 & .302 & .909 & .091 & .059 \\
Question2 & .302 & .909 & .091 & .059 \\
Question3 & .286 & .862 & .047 & .280 \\
Question4 & .773 & .465 & .204 & .084 \\
Question5 & .940 & .241 & .141 & .010 \\
Question6 & .908 & .235 & .157 & .008 \\
Question7 & .929 & .252 & .140 & .012 \\
Question8 & .201 & .089 & .962 & -.048 \\
Question9 & .177 & .085 & .967 & -.055 \\
Question10 & .033 & .080 & -.043 & .854 \\
Question11 & .004 & .144 & -.044 & .853 \\
\hline
\end{tabular}

Extraction Method: Principal Component Analysis.

Rotation Method: Varimax with Kaiser Normalization.

a. Rotation converged in 5 iterations.

\section{Results and conclusions}

In this paper, through questionnaire survey, statistical analysis, etc., four dimensions that influence campus recruitment effectiveness are finally determined from the perspective of graduating students, namely, work ability, job-hunting skills, job expectations and adaptability. The sub-factors include resume authenticity, interview preparation, corporate image and prestige, job development space, job salary and welfare level, environmental adaptability, ability to adapt to work and practical work ability.

According to the above analysis, to improve effectiveness of campus recruitment, graduating students should pay attention to the following aspects: first of all, pay attention to work ability, participate in some social activities to exercise oneself, to lay the foundation for post-entry work ability; secondly, improve ability to adapt in a changing environment; finally, in the job-hunting, on the one hand, avoid carelessly dealing with resume crafting, and on the other hand, make good preparation to fully display oneself in the interview. In addition, enterprises practicing campus recruitment can attract more candidates by enhancing brand image, providing multiple salary incentives and job promotion channels, thereby enhancing signing rate and effectiveness of campus recruitment.

\section{References}

[1] Wang Youping, Ye Fangbin. Problems in campus recruitment and countermeasures [J]. Human Resource Management, 2010, (10).

[2] Yao Tianzeng, Li Haipeng, Cui Changhua. Problems in enterprises' campus recruitment and countermeasures [J]. Journal of Shanxi Teachers University, 2011, (38). 
[3] Yang Gang. Improve effectiveness of campus recruitment [J]. CO-Operative Economy \& Science, 2009, (369).

[4] He Ying, Yan Chunfang. Consideration on improving effectiveness of campus recruitment [J]. Pioneering with Science \& Technology Monthly, 2014, (3).

[5] Zhang Xiaochun. Research on influencing factors of effectiveness of enterprise campus recruitmentquestionnaire from enterprise point of view [J] .Jiangsu Commercial Forum, 2014, (8).

[6] Gao Yumei. Simple comments on campus recruitment activities in colleges and universities [J]. Education Exploration, 2011, (2). 